\title{
O GÊNERO OENOTHERA L. (ONAGRACEAE) NO MUNICÍPIO DE SANTA MARIA, RIO GRANDE DO SUL, BRASIL.
}

\author{
DANIELE GRIGOLETTO ${ }^{1}$ TATIANE BERTUZZI ${ }^{2}$ THAÍS SCOTTI DO CANTO-DOROW ${ }^{3}$ \\ SÔNIA MARIA EISINGER ${ }^{4}$
}

\begin{abstract}
RESUMO
O estudo do gênero Oenothera L. no município de Santa Maria, Rio Grande do Sul, Brasil, revelou a ocorrência de cinco espécies. $\mathrm{O}$ trabalho apresenta chave para diferenciação das espécies, ilustrações e dados de suas distribuições geográficas.

Palavras-chave: Oenothera, Onagraceae, Santa Maria, Rio Grande do Sul.
\end{abstract}

\section{ABSTRACT}

[The genus Oenothera L. (Onagraceae) in the municipality of Santa Maria, Rio Grande do Sul, Brazil].

The study of the genus Oenothera L. in the municipality of Santa Maria, Rio Grande do Sul state, Brazil, confirmed the occurrence of five species. A analytical key to differenciate species is provided, as well as illustrations and data about the geographic distribution.

Key words: Oenothera, Onagraceae, Santa Maria, Rio Grande do Sul.

\section{INTRODUÇÃO}

A família Onagraceae é dividida em duas subfamílias, Ludwigioideae e Onagroideae. A subfamília Ludwigioideae apresenta uma única tribo, Jussieeae, tendo Ludwigia L. como único gênero e a subfamília Onagroideae apresenta seis tribos: Hauyeae (um gênero), Circaeeae (dois), Lopeziae (dois), Gongylocarpeae (um), Epilobiae (dois) e Onagreae (treze), na qual está inserida o gênero Oenothera L. (Wagner et al., 2007). Essa família possui cerca de 650 espécies distribuídas nas regiões subtropicais e temperadas (Salomon \& Dietrich, 1984), espécies essas predominantemente americanas (Cabrera, 1965), com o máximo de abundância e diversificação no Oeste dos Estados Unidos (Cronquist, 1981).

1 Acadêmica do curso de Graduação em Ciências Biológicas, Universidade Federal de Santa Maria, Santa Maria, RS, Brasil. danielegrigoletto@ hotmail.com

2 Acadêmica do curso de Graduação em Ciências Biológicas, Universidade Federal de Santa Maria, Santa Maria, RS, Brasil. tati_bertuzzi@hotmail.com

3 Bióloga, Dra., Prof ${ }^{\circ}$. Associado do Departamento de Biologia, Universidade Federal de Santa Maria, Santa Maria, RS, Brasil. thaisdorow@gmail.com

${ }^{4}$ Bióloga, Dra., Prof ${ }^{\mathrm{o}}$. Associado do Departamento de Biologia, Universidade Federal de Santa Maria, Santa Maria, RS, Brasil. soniame@ccne.ufsm.br
O gênero Oentohera inclui cerca de 130 espécies (Salomon \& Dietrich, 1984), de distribuição coincidindo com a citada acima para a família.

No Brasil, há registros de aproximadamente 50 espécies da família Onagraceae, concentradas nas regiões Sul e Sudeste, distribuídas em quatro gêneros: Fuchsia L., Epilobium L., Ludwigia e Oenothera (Falkenberg, 1988).

Segundo Souza \& Lorenzi (2008), o gênero Oenothera ocorre por todo o Brasil, estando mais associado à região litorânea.

Salomon \& Dietrich (1984) citaram quatro gêneros de Onagraceae para Santa Catarina, enfatizando somente Epilobium (uma espécie) e Oenothera ( $O$. affinis Cambess., $O$. catharinensis Cambess., O. indecora Cambess. subsp. bonariensis W. Dietr., O. indecora Cambess. subsp. indecora, $O$. mollissima L., $O$. parodiana Munz. subsp. brasiliensis W. Dietr. e $O$. ravenii W. Dietr. subsp. ravenii).

No Rio Grande do Sul, Falkenberg (1988) apresentou uma revisão do gênero Oenothera, descrevendo sete táxons ( $O$. affinis, $O$. indecora Cambess., O. mendocinensis Gillies ex Hook. \& Arn., O. mollissima, O. parodiana Munz. 
subsp. parodiana, $O$. parodiana subsp. brasiliensis e $O$. ravenii $\mathrm{W}$. Dietr.), inclusive com novas ocorrências e referiu, sem fazer comentários, 15 espécies de Ludwigia. Nessa publicação há citação de outros autores, os quais mencionaram ainda para o estado, Epilobium hirtigerum A. Cunn. (Salomon, 1982 apud Falkenberg, 1988) e Fuchsia regia (Vellozo) Munz (Berry, 1988 apud Falkenberg, 1988). Nesse mesmo trabalho, a ocorrência de $O$. indecora e $O$. ravenii foram citadas para o município de Santa Maria e também para outros municípios.

Falkenberg (1988) referiu valor medicinal para $O$. mollissima (aperitiva, adstringente e vulnerária), enquanto Cronquist (1981) citou espécies cultivadas como ornamentais.

Este estudo visa a colaborar para o conhecimento do gênero Oenothera no município de Santa Maria, pois há escassez de meios para a identificação de seus representantes, principalmente chaves analíticas e descrições morfológicas com ilustrações.

\section{MATERIAL E MÉTODOS}

O estudo foi realizado no município de Santa Maria, localizado entre os paralelos $29^{\circ} 43^{\prime} 57^{\prime \prime}$ e $29^{\circ} 55^{\prime} 30^{\prime \prime} \mathrm{S}$ e os meridianos $53^{\circ} 42^{\prime} 13^{\prime \prime}$ e $53^{\circ} 48^{\prime} 02^{\prime}$ 'W, na região da Depressão Central do estado do Rio Grande do Sul. O clima da região é do tipo Cfa (temperado úmido) de acordo com a classificação de Köppen (Moreno, 1961 apud Heldwein et al., 2009).
As classes de solos predominantes no município são Argissolos, Planossolos, Gleissolos e Neossolos (Dalmolin \& Pedron, 2009).

A vegetação caracteriza-se por florestas, na encosta da Serra Geral, e campos naturais entremeados de matas ciliares e capões, nas planícies e coxilhas da Depressão Central (Marchiori, 2009).

Foram realizadas coletas mensais, em áreas abertas na região de Santa Maria, incluindo campos de solos bem e mal drenados, beira de estradas e terrenos baldios, durante o período de março de 2009 a março de 2010. Os exemplares coletados foram fotografados no campo e herborizados para posterior identificação e inclusão no herbário SMDB.

A identificação e descrição do material foram estabelecidas, principalmente, com base nos trabalhos de Salomon \& Dietrich (1984), Falkenberg (1988) e Wagner et al. (2007) e, a terminologia morfológica, seguiu Barroso et al. (1999) e Gonçalves \& Lorenzi (2007). Além disso, foram utilizadas comparações com materiais depositados nos herbários HUCS, ICN e SMDB, conforme Holmgren et al. (1990).

Os dados de distribuição geográfica foram retirados da literatura e do material examinado e, os dados de ambiente, foram baseados nas informações contidas nas etiquetas dos herbários revisados e em observações a campo.

As ilustrações foram feitas a partir de cópias reprográficas de exemplares herborizados e posterior desenho a nanquim em papel vegetal.

\section{RESULTADOS}

\section{Chave para a identificação de gêneros da família Onagraceae ocorrentes em Santa Maria.}

1a. Presença de prolongamento do hipanto acima do ovário (tubo floral); sépalas não persistentes no fruto; estigma quadrissecto; estípulas ausentes Oenothera

1b. Ausência de prolongamento do hipanto acima do ovário; sépalas persistentes no fruto; estigma inteiro, capitado; estípulas presentes Ludwigia 


\section{Descrição do gênero Oenothera $\mathbf{L}$.}

Ervas a subarbustos, ocorrem, preferencialmente, em solos bem drenados. Folhas basais em roseta ou não, folhas superiores alternas, de margem leve a fortemente dentada; estípulas, ausentes. Hipanto prolongado acima do ovário (tubo floral), decíduo no fruto. Flores tetrâmeras, actinomorfas; sépalas totalmente livres entre si, ou frequentemente conatas, reflexas; pétalas amarelas, podendo tornar-se vermelhas ou alaranjadas após a antese, dialipétalas; diplostêmone; ovário ínfero, tetralocular, estilete filiforme, estigma quadrissecto; sementes abundantes, plurisseriadas em cada lóculo, placentação axial; cápsula rompente (as sementes são liberadas durante a desintegração das paredes do fruto). Florescem principalmente na primavera e no verão.

\section{Chave para a identificação de espécies de Oenothera L. ocorrentes em Santa Maria.}

1a. Tubo floral e pétalas com até $1 \mathrm{~cm}$ compr. 2. O. indecora

1b. Tubo floral e pétalas maiores que $1 \mathrm{~cm}$ compr.

2a. Folhas geralmente concentradas na base da planta, formando roseta, caducas ou não durante o período de floração. Caule hirsuto-pubescente, tricomas grossos e fortes, de base tuberculada.

3a. Tubo floral 2,3-4 cm compr.; filetes $0,7-1,6 \mathrm{~cm}$ compr.; estilete $3-4,7 \mathrm{~cm}$ compr. 4. O. parodiana subsp. brasiliensis

3b. Tubo floral 3-4,8 cm compr.; filetes 1,3-1,8 cm compr.; estilete 4,2-6,1 cm compr. 5. O. ravenii

2b. Folhas em roseta, ausentes na base da planta. Caule hirsuto-pubescente, tricomas finos e macios de base não tuberculada.

4a. Tubo floral 2,3-3,2 cm compr.; sépalas 0,9-1,9 cm compr.; pétalas 1,4-2,4 cm compr. Folhas superiores de base truncada ou arredondada

4b. Tubo floral 7,2-10,5 cm compr.; sépalas 2,2-3,3 cm compr.; pétalas 2,4-3,2 cm compr. Folhas superiores de base fortemente atenuada .... 1. O. affinis

1. Oenothera affinis Cambess., Fl. Bras. Merid. (Quarto ed.) 2: 269. 1829.

Ervas a subarbustos com até $85 \mathrm{~cm}$ de altura, eretos, não ramificados na base ou ramificados superiormente a partir do caule principal, podendo ter hábito decumbente, com elevação dos ramos florais (Figuras 1A, 1C, 1D). Caule densamente piloso, hirsuto-pubescente; tricomas finos e macios de base não tuberculada. Folhas em roseta, ausentes; folhas superiores 2,5-12 cm compr., 0,5-2,5 cm larg., estreitoelípticas a lanceoladas, base fortemente atenuada, margem leve a fortemente dentada, sésseis, pilosidade homogênea, densa e curta, consistência macia e aveludada; brácteas $2,5-9 \mathrm{~cm}$ compr., 0,5-1,7 cm larg., lanceoladas, base arredondada, margem leve a fortemente dentada, sésseis, geralmente maiores do que o fruto. Tubo floral
7,2-10,5 cm compr., esparsamente piloso; sépalas 2,2-3,3 cm compr., densamente pilosas; pétalas 2,4-3,2 cm compr.; filetes $0,8-1,9 \mathrm{~cm}$ compr.; anteras 0,9-1,2 cm compr.; ovário 1-2,5 cm compr., densamente piloso; estilete 10-13 cm compr.; ramos do estigma $0,5-0,8 \mathrm{~cm}$ compr. (Figura 1B). Cápsula obovada, 1,7-4 cm compr., densamente pilosa.

Período de floração e frutificação: setembro a fevereiro.

Material coletado: BRASIL: RIO GRANDE DO SUL: Santa Maria, linha da fronteira, Guilherme Rau s/nº 11.XI.1947 (SMDB 485); Camobi, D. Grigoletto et al. 19, 25.IX.2009 (SMDB 12.553); próximo do trevo de São Pedro, D. Grigoletto et al. 18, 25.IX.2009 (SMDB 12.653); São Sebastião, próximo da ponte localizada perto do Fighera, D. Grigoletto 


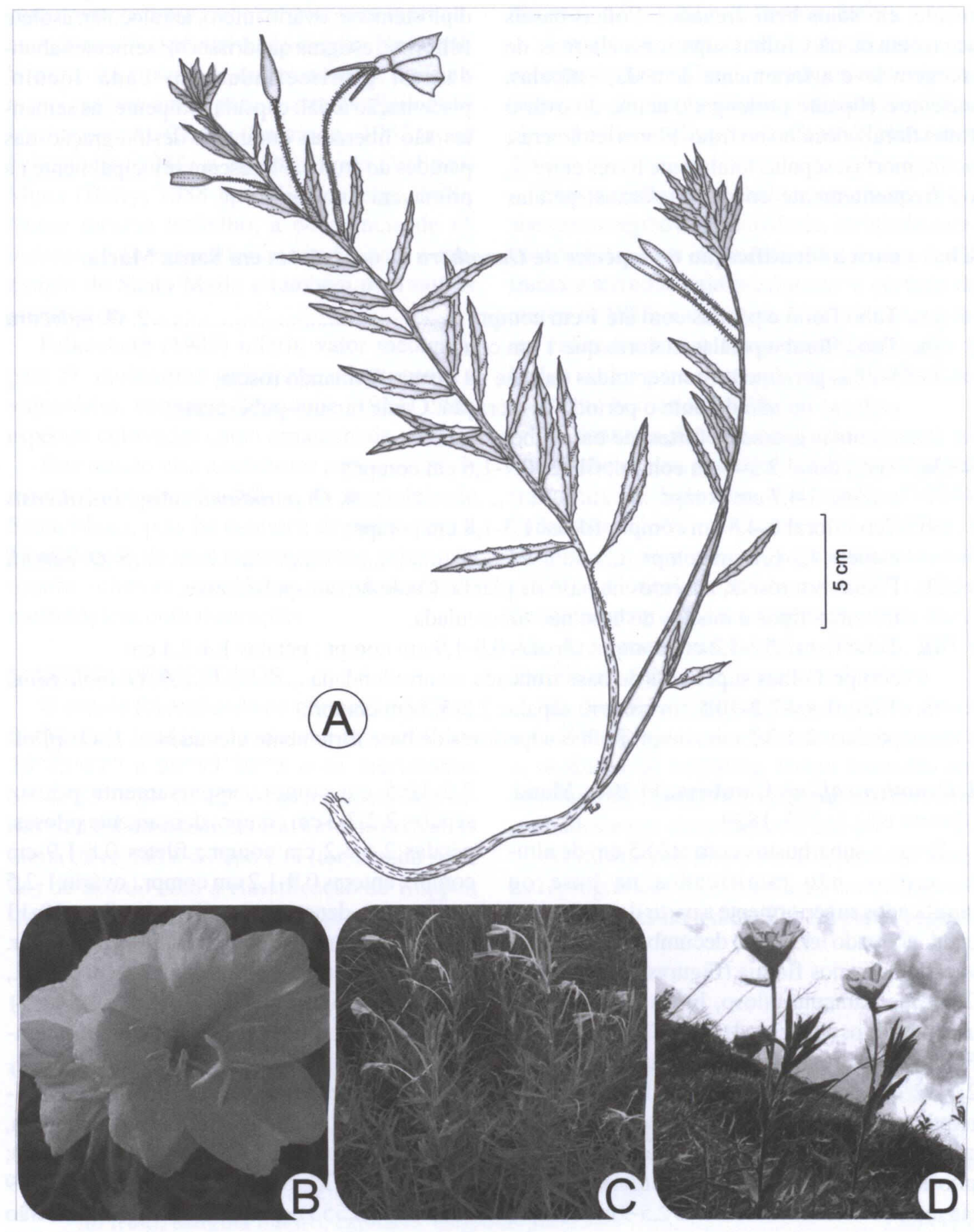

FIGURA 1 - Oenothera affinis. A - Hábito. B - Detalhe da flor. C - Vista geral da população. D - Detalhe dos ramos florais. (Bertuzzi T. et al., 18 - SMDB). 
et al. 22, 05.X.2009 (SMDB 12.649); BR 392, T. Bertuzzi et al. 21 09.X.2009 (SMDB 12.654); BR 392, T. Bertuzzi et al. 23, 09.X.2009 (SMDB 12.653); Camobi, Faixa Nova, em frente ao Supermercado Atacado, T. Bertuzzi et al. 18, 09.X.2009 (SMDB 12.648); São Sebastião, próximo da ponte localizada perto do Fighera, T. Bertuzzi et al. 26, 09.X.2009 (SMDB 12.651).

Distribuição no Rio Grande do Sul: Alegrete, Cachoeira do Sul, Caxias do Sul, Guaíba, Giruá, Ijuí, Tenente Portela, Santiago, São Francisco de Assis, São Pedro do Sul e Uruguaiana.

2. Oenothera indecora Cambess., Fl. Bras. Merid. (Quarto ed.) 2: 268. 1830.

Ervas a subarbustos com até $60 \mathrm{~cm}$ de altura, eretos, ramificados a partir do caule principal (Figura 2A). Caule densamente piloso, hirsuto-pubescente; tricomas finos e macios, de base não tuberculada. Folhas em roseta geralmente ausentes; folhas superiores 3,2-6,5 cm compr., 0,3-1 cm larg., lanceoladas, base obtusa, margem leve a fortemente dentada, sésseis, tricomas curtos e esparsos em ambas as faces, tricomas mais longos sobre a nervura principal; brácteas 1-5,5 cm compr., 0,3-1 cm larg., lanceoladas, base obtusa, margem leve a fortemente dentada, sésseis, geralmente maiores do que o fruto. Tubo floral $0,5-1 \mathrm{~cm}$ compr., esparsamente piloso; sépalas $0,5-1 \mathrm{~cm}$ compr., densamente pilosas; pétalas $0,4-1 \mathrm{~cm}$ compr.; filetes $0,3-0,7 \mathrm{~cm}$ compr.; anteras $0,2-0,4 \mathrm{~cm}$ compr.; ovário 0,5-1 cm compr., densamente piloso; estilete 1-1,5 cm compr.; ramos do estigma 0,1-0,2 cm compr. (Figura 2B). Cápsula linear a obovada, 1,2-2,3 cm compr., densamente pilosa (Figura 2C).

Período de floração e frutificação: agosto a maio.

Material coletado: BRASIL: RIO GRANDE DO SUL: Santa Maria, Pau Fincado, Fazenda S. Cristina, Romeu Beltrão s/n $\mathrm{n}^{\circ}$, 4.III.1952 (SMDB 698); Campus UFSM, Matos A. C. F. et al. $\mathrm{s} / \mathrm{n}^{\circ}$, 03.IX.1993 (SMDB, 4861); Campus UFSM, Rangel I. et al. $\mathrm{s} / \mathrm{n}^{\circ}, 14 . I X .1993$ (SMDB 4901); Campus UFSM, I. Rangel et al. $\mathrm{s} / \mathrm{n}^{\circ}$,
07.X.1993 (SMDB 4848); Campus UFSM, Ethur L. Z. s/no , 24.XI.1994 (SMDB 5414); Camobi, Faixa Nova, T. Bertuzzi et al. 17, 30.IX.2009 (SMDB 12.634); BR 392, T. Bertuzzi et al. 22, 09.X.2009 (SMDB 12.635); Camobi, Faixa Nova, em frente a Rede Vivo, T. Bertuzzi et al. 19, 09.X.2009 (SMDB 12.633); Camobi, Faixa Nova, trevo para as Dores, T. Bertuzzi et al. $\mathrm{s} / \mathrm{n}^{\circ}, 09 . X .2009$ (SMDB 12.551); em frente ao Posto Rodoviário de Camobi, D. Grigoletto et al. 24, 23.X.2009 (SMDB 12.632).

Distribuição no Rio Grande do Sul: Agudo, Cachoeira do Sul, Caçapava do Sul, Camaquã, Cruzeiro do Sul, Dom Feliciano, Encruzilhada do Sul, Imbé, Itaqui, Nova Prata, Osório, Pelotas, Porto alegre, Quaraí, Taquara, Tramandaí e Viamão.

3. Oenothera mollissima L., Sp. Pl. 1: 346. 1753.

Ervas a subarbustos com até $150 \mathrm{~cm}$ de altura, eretos, não ramificados na base ou ramificados superiormente a partir do caule principal (Figuras 3A, 3D). Caule densamente piloso, hirsuto-pubescente; tricomas finos e macios, de base não tuberculada. Folhas em roseta caducas, ausentes na maturidade (Figura $3 \mathrm{E}$ ); folhas superiores $2,7-13 \mathrm{~cm}$ compr., 0,7$2,1 \mathrm{~cm}$ larg., estreito-elípticas a lanceoladas, base truncada ou arredondada, margem leve a fortemente dentada, sésseis, pilosidade homogênea, densa e curta, consistência macia e aveludada, tricomas geralmente mais concentrados sobre a nervura principal e margem da folha; brácteas 0,9-5,9 cm compr., 0,5-1 cm larg., lanceoladas, base arredondada ou truncada, margem leve a fortemente dentada, sésseis, menores, iguais ou maiores do que o fruto. Tubo floral 2,3-3,2 cm compr., esparsamente piloso; sépalas 0,9-1,9 cm compr., densamente pilosas; pétalas 1,4-2,4 cm compr.; filetes $0,8-1,4 \mathrm{~cm}$ compr.; anteras 0,6-0,9 cm compr.; ovário 0,9$2,5 \mathrm{~cm}$ compr., densamente piloso; estilete 3$4,4 \mathrm{~cm}$ compr.; ramos do estigma $0,3-0,8 \mathrm{~cm}$ compr. (Figura 3B). Cápsula obovada, 1,2-3,4 cm compr., densamente pilosa (Figura 3C). 

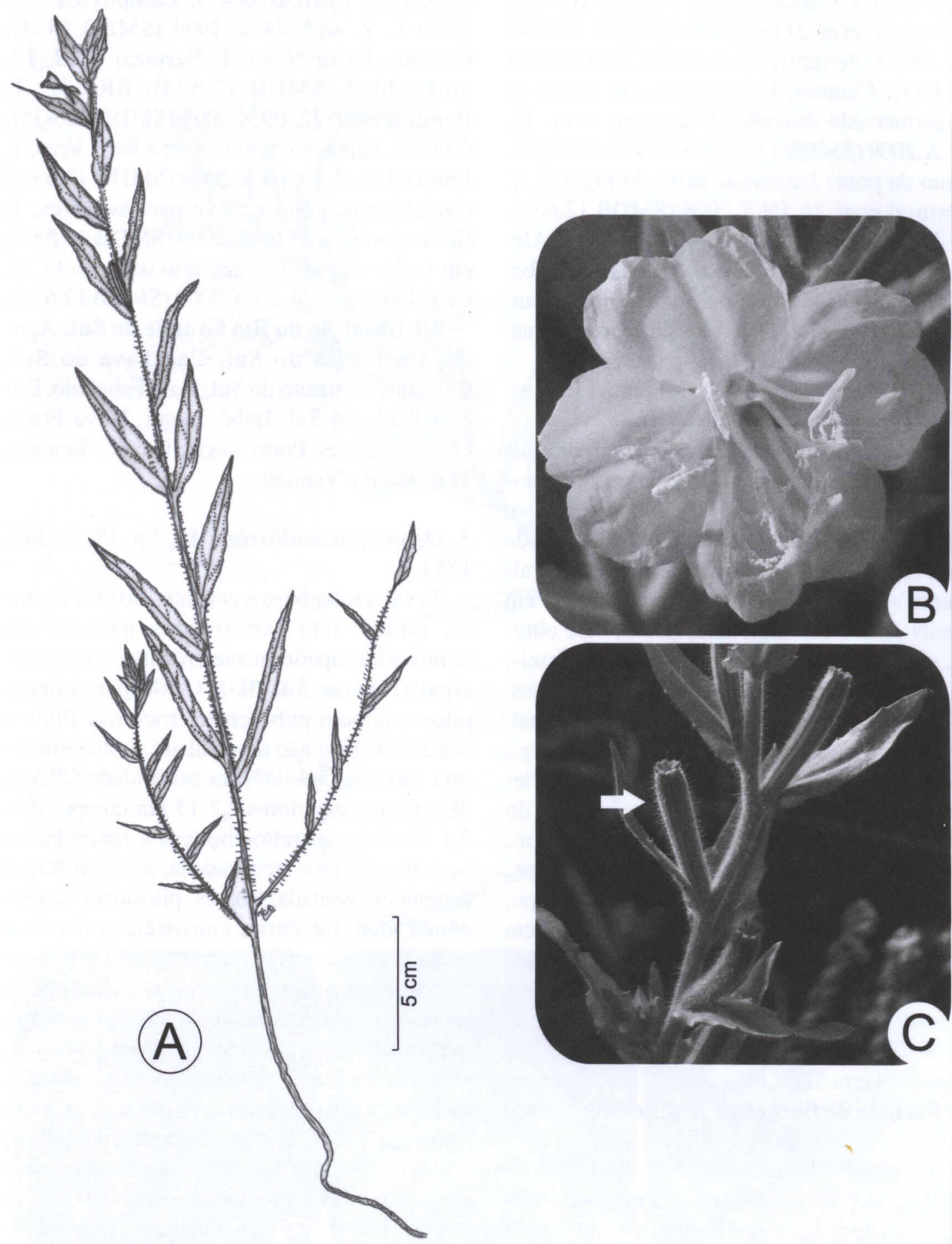

FIGURA 2 - Oenothera indecora. A - hábito. B - Detalhe da flor. C - Detalhe do fruto jovem (seta). (Grigoletto D. et al., 19 e 24 - SMDB). 

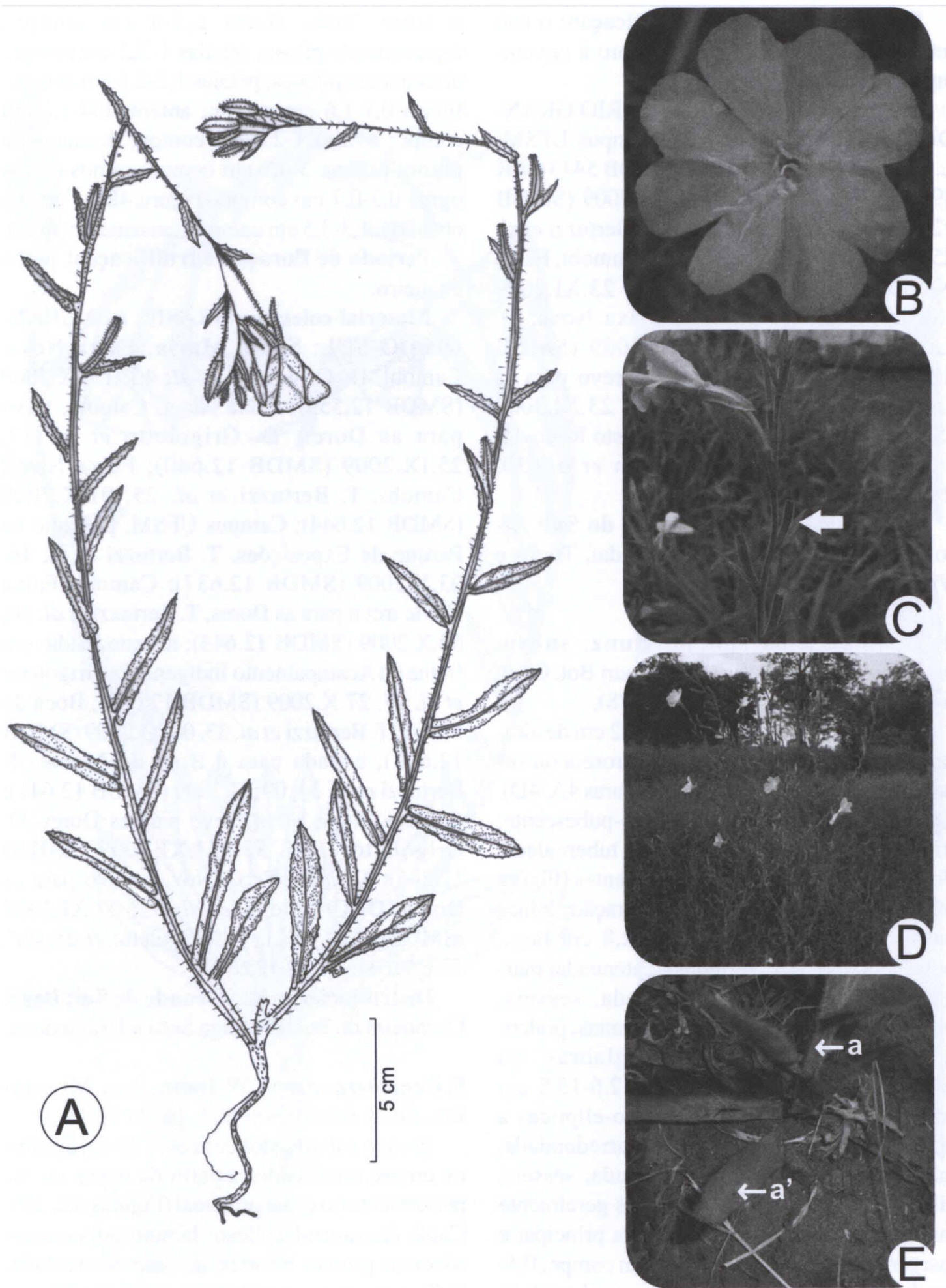

FIGURA 3 - Oenothera molissima. A - Hábito. B - Detalhe da flor. C - Detalhe do fruto jovem (seta). D - Vista geral da planta. E - a: escapo floral, a': folhas caducas na roseta. (Grigoletto D. et al., 39 -SMDB). 
Período de floração e frutificação: o ano inteiro, com predomínio de outubro a novembro.

Material coletado: BRASIL: RIO GRANDE DO SUL: Santa Maria, Campus UFSM, L. Z. Ethur $\mathrm{s} / \mathrm{n}^{\circ}, 24$.XI.1994 (SMDB 5413); BR 392, T. Bertuzzi et al. 21, 09.X.2009 (SMDB 12.628); Camobi, Faixa Nova, T. Bertuzzi et al. 25, 24.X.2009 (SMDB 12.627); Camobi, Faixa Nova, D. Grigoletto et al. 36, 23.XI.2009 (SMDB 12.630); Camobi, Faixa Nova, D. Grigoletto et al. 39, 23.XI.2009 (SMDB 12.552); Camobi, Faixa Nova, trevo para as Dores, D. Grigoletto et al. 34, 23.XI.2009 (SMDB 12.629); em frente ao Posto Rodoviário de Camobi, D. Grigoletto et al. 30, 23.XI.2009 (SMDB 12.631).

Distribuição no Rio Grande do Sul: Arroio do Sal, Rio Grande, Tramandaí, Torres e Viamão.

4. Oenothera parodiana Munz. subsp. brasiliensis W. Dietr., Ann. Missouri Bot. Gard. 64 (3): 570-574, f. 147. 1977 (1978).

Ervas a subarbustos com até $122 \mathrm{~cm}$ de altura, eretos, ramificados a partir da roseta ou superiormente no caule principal (Figuras 4A, 4D). Caule densamente piloso, hirsuto-pubescente; tricomas grossos e fortes, de base tuberculada. Folhas em roseta, geralmente presentes (Figura 4C), caducas ou não durante a floração; folhas basais 4,5-17 cm compr., 0,6-2,8 cm larg., oblanceoladas, base fortemente atenuada, margem leve a fortemente dentada, sésseis, pilosidade densa semelhante às demais, podendo também apresentar-se glabras ou glabrescentes; folhas superiores $2,6-13,5 \mathrm{~cm}$ compr., 0,7-2,1 cm larg., estreito-elípticas a lanceoladas, base subcordada a arredondada, margem leve a fortemente dentada, sésseis, pilosidade densa e curta, tricomas geralmente mais concentrados sobre a nervura principal e margem da folha; brácteas 1-2,7 cm compr., 0,5$1 \mathrm{~m}$ larg., lanceoladas a ovadas, base subcordada a arredondada, margem leve a fortemente dentada, sésseis, menores, iguais ou maiores do que o fruto. Tubo floral 2,3-4 cm compr., esparsamente piloso; sépalas 1-2,2 cm compr., densamente pilosos; pétalas 1,2-2,6 cm compr.; filetes $0,7-1,6 \mathrm{~cm}$ compr.; anteras $0,4-1,2 \mathrm{~cm}$ compr.; ovário 1-2,4 cm compr., densamente piloso; estilete $3-4,7 \mathrm{~cm}$ compr.; ramos do estigma 0,3-0,7 cm compr. (Figura 4B). Cápsula obovada, 1,3-3,5 cm compr., densamente pilosa.

Período de floração e frutificação: junho a janeiro.

Material coletado: BRASIL: RIO GRANDE DO SUL: Santa Maria, Faixa Nova, Camobi, D. Grigoletto et al. 40, 15.IX.2009 (SMDB 12.555); Faixa Nova, Camobi, trevo para as Dores, D. Grigoletto et al. 17, 25.IX.2009 (SMDB 12.640); Faixa Nova, Camobi, T. Bertuzzi et al. 25, 01.X.2009 (SMDB 12.644); Campus UFSM, próximo ao Parque de Exposições, T. Bertuzzi et al. 16, 03.X.2009 (SMDB 12.637); Camobi, Faixa Nova, trevo para as Dores, T. Bertuzzi et al. 20, 09.X.2009 (SMDB 12.643); terreno baldio em frente ao Acampamento Indígena, D. Grigoletto et al. 27, 27.X.2009 (SMDB 12.647); Boca do Monte, T. Bertuzzi et al.33, 08.XI.2009(SMDB 12.642); estrada para a Boca do Monte, $T$. Bertuzzi et al.34, 09.XI.2009 (SMDB 12.641); Camobi, Faixa Nova, trevo para as Dores, D. Grigoletto et al. 33, 23.XI.2009 (SMDB 12.646); Camobi, Faixa Nova, trevo para as Dores, D. Grigoletto et al. 35, 23.XI.2009 (SMDB 12.645); s.l., D. Grigoletto et al. s/ $\mathrm{n}^{\circ}$, 17.I.2010 (SMDB 12.638).

Distribuição no Rio Grande do Sul: Bagé, Cachoeira do Sul, Restinga Seca e Uruguaiana.

5. Oenothera ravenii W. Dietr., Ann. Missouri Bot. Gard. 64 (3): 500-503. 1977 (1978).

Ervas a subarbustos com até $120 \mathrm{~cm}$ de altura, eretos, ramificados a partir da roseta ou superiormente no caule principal (Figuras 5A, 5E). Caule densamente piloso, hirsuto-pubescente; tricomas grossos e fortes, de base tuberculada. Folhas em roseta, geralmente presentes (Figura 5D), caducas ou não durante a floração; folhas basais 9,5-22 cm compr., 0,7-2,3 cm larg., es- 

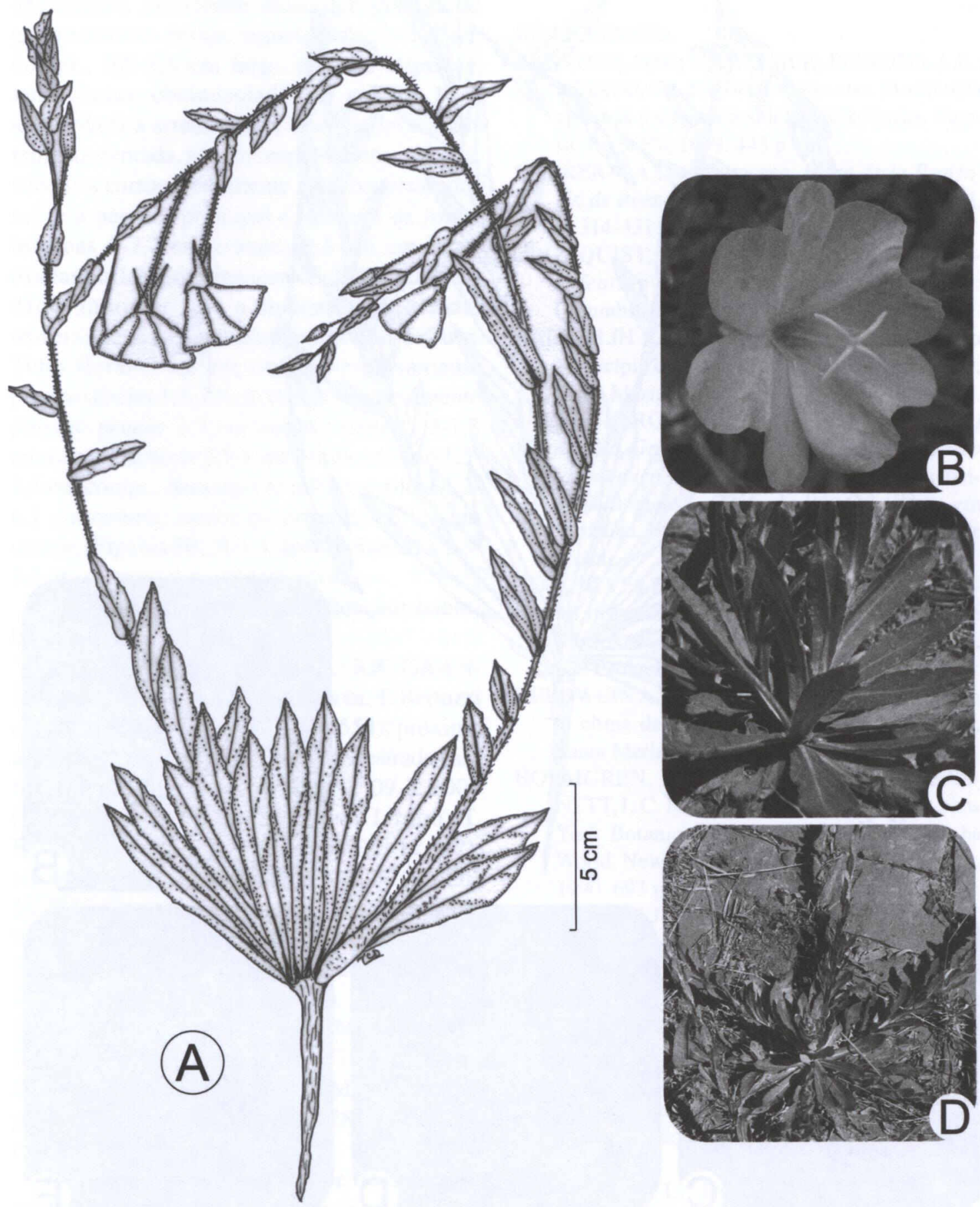

FIGURA 4 - Oenothera parodiana subsp. brasiliensis. A - Hábito. B - Detalhe da flor. C - Detalhe da roseta. D - Vista geral do hábito. (Grigoletto D. et al., 40 -SMDB). 


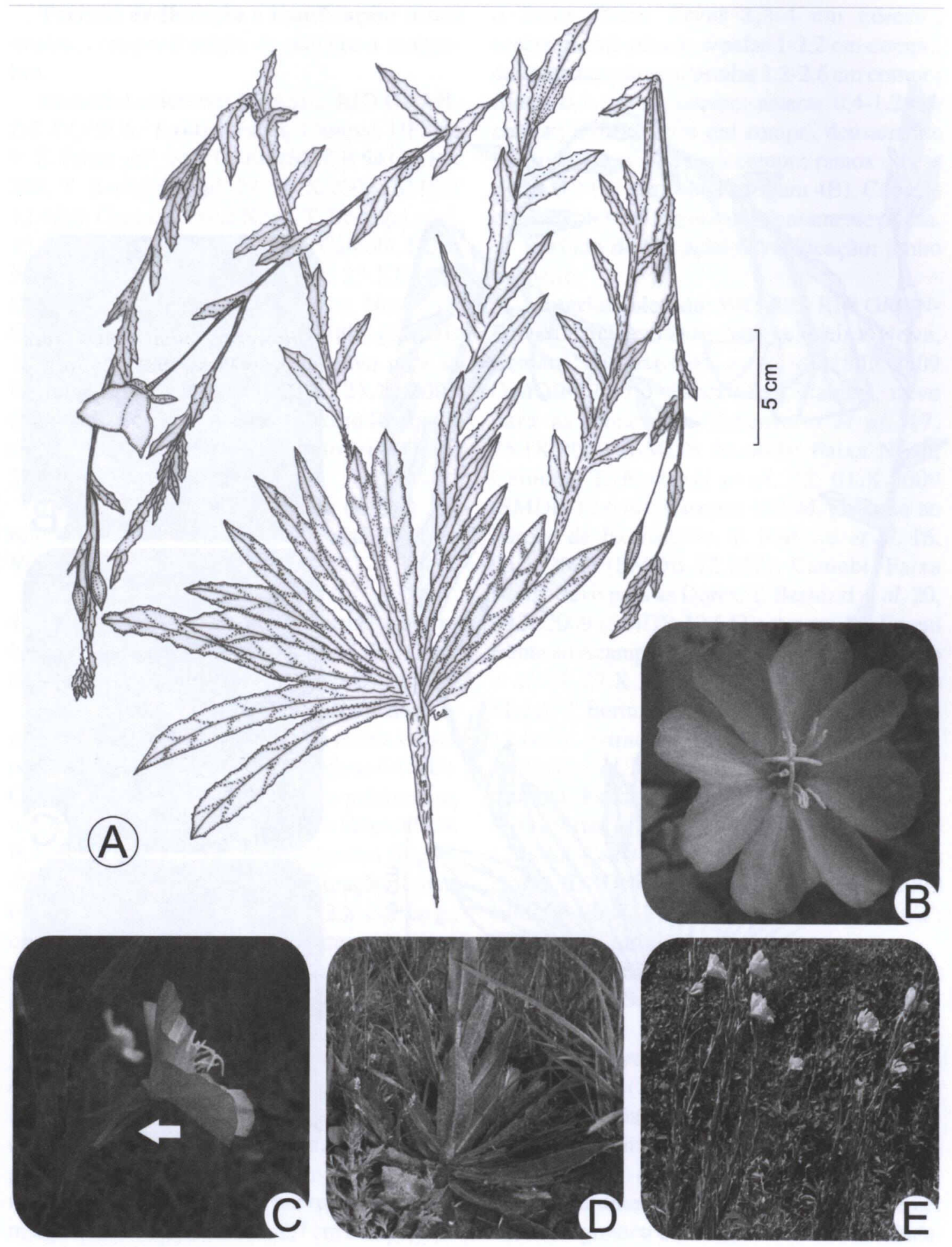

FIGURA 5 - Oenothera ravenii. A - Hábito. B - Detalhe da flor. C - Sépalas reflexas (seta). D - Detalhe da roseta. E - vista geral da população. (Bertuzzi T. et al., 24 - SMDB). 
treito-elípticas a oblanceoladas, base fortemente atenuada, margem leve a fortemente dentada, sésseis, pilosidade densa até glabras ou glabrescentes; folhas superiores $1,5-11,5 \mathrm{~cm}$ compr., 0,5-2,6 cm larg., estreito elípticas, lanceoladas, oblanceoladas ou ovadas, base subcordada a arredondada, margem leve a fortemente dentada, sésseis, esparsamente pilosas, tricomas curtos, geralmente mais concentrados sobre a nervura principal e margem da folha; brácteas 1-3,2 cm compr., 0,4-1,6 cm larg., ovadas ou deltóides, base subcordada a arredondada, margem leve a fortemente dentada, sésseis, geralmente menores do que o fruto. Tubo floral 3-4,8 cm compr., esparsamente piloso; sépalas 1,5-2,8 cm compr., esparsamente pilosas; pétalas 2-3 cm compr.; filetes 1,3-1,8 $\mathrm{cm}$ compr., anteras 0,5-1 cm compr.; ovário 1,5$2,5 \mathrm{~cm}$ compr., densamente piloso; estilete $4,2-$ $6,1 \mathrm{~cm}$ compr.; ramos do estigma $0,5-0,7 \mathrm{~cm}$ compr. (Figuras 5B, 5C). Cápsula obovada, 1,83,6 cm compr., densamente pilosa.

Período de floração e frutificação: setembro a maio.

Material coletado: BRASIL: RIO GRANDE DO SUL: Santa Maria, Camobi, T. Bertuzzi et al. 47, 15.IX.2009 (SMDB 12.554); próximo ao trevo de acesso para Santa Maria, estrada para São Sepé, T. Bertuzzi et al. 24, 09.X.2009 (SMDB 12.625); Avenida Silva Jardim, T. Bertuzzi et al. 28, 14.X.2009 (SMDB 12.622); s.1., D. Grigoletto et al. 23, 21.X.2009 (SMDB 12.621); Camobi, Faixa Velha, Km 3, terreno baldio próximo a sinaleira, D. Grigoletto et al. 26, 21.X.2009 (SMDB 12.624); Campus UFSM, estrada para o Jardim Botânico, T. Bertuzzi et al. 31, 24.X.2009 (SMDB 12.626); Boca do Monte, T. Bertuzzi et al.33, 08.XI.2009 (SMDB 12.620); Campus UFSM, próximo ao prédio 16, D. Grigoletto et al. 28, 13.XI.2009 (SMDB 12.623).

Distribuição no Rio Grande do Sul: Alegrete, Arroio dos Ratos, Capão da Canoa, Eldorado do Sul, Jaguari, Jaguarão, Pelotas,
Porto Alegre, Santo Ângelo, São Francisco de Assis e Torres.

\section{BIBLIOGRAFIA}

BARROSO, G.M.; MARIN, M.P.; PEIXOTO, A.L.; ICHASO, C.L.F. Frutos e sementes. Morfologia aplicada à sistemática de dicotiledôneas. Viçosa: Ed. UFV, 1999. 443 p.

CABRERA, A.L. Onagraceae. Flora de la Província de Buenos Aires. Buenos Aires: INTA, v. 4, p. 314-331, 1965.

CRONQUIST, A. An integrated system of classification of flowering plants. New York: Columbia University Press, 1981. 1262 p.

DALMOLIN R.S.D.; PEDRON F. de A. Solos do Município de Santa Maria. Ciência\&Ambiente, Santa Maria, n. 38, p. 59-78, 2009.

FALKENBERG, D.B. Oenothera L. (Onagraceae) do Rio Grande do Sul, Brasil - um estudo taxonômico. 1988. 113 f. Mestrado em Ciências Biológicas - Curso de Pós-Graduação em Botânica, Universidade Federal do Rio Grande do Sul.

GONÇALVES E.G.; LORENZI H. Morfologia Vegetal: Organografia e Dicionário Ilustrado de Morfologia das Plantas Vasculares. Nova Odessa, São Paulo: Instituto Plantarum, 2007. 448 p.

HELDWEIN A.B.; BURIOL, G.A.; STRECK, N.A. O clima de Santa Maria. Ciência\&Ambiente, Santa Maria, n. 38, p. 43-58, 2009.

HOLMGREN, P.K.; HOLMGREN, N.H.; BARNETT, L.C. Index Herbariorum. $8^{a}$ edição. New York Botanical Garden. The Herbaria of the World. New York: New York Botanical Garden, 1990. $693 \mathrm{p}$.

MARCHIORI J.N.C. A vegetação em Santa Maria. Ciência\&Ambiente, Santa Maria, n. 38, p. 93112, 2009.

SALOMON, J.C.; DIETRICH, W. Onagráceas. In: REITZ, R. Flora Ilustrada Catarinense. Itajaí: Herbário "Barbosa Rodrigues", 20 dez. 1984. $33 \mathrm{p}$.

SOUZA, V.C.; LORENZI, H. Botânica Sistemática. $2^{\mathrm{a}}$ edição. São Paulo: Instituto Plantarum, 2008. $293 \mathrm{p}$.

WAGNER, W.L.; HOCH, P.C.; RAVEN, P.H. Revised classification of the Onagraceae. Systematic Botany Monographs, n.83, p. 1-240, 2007. 